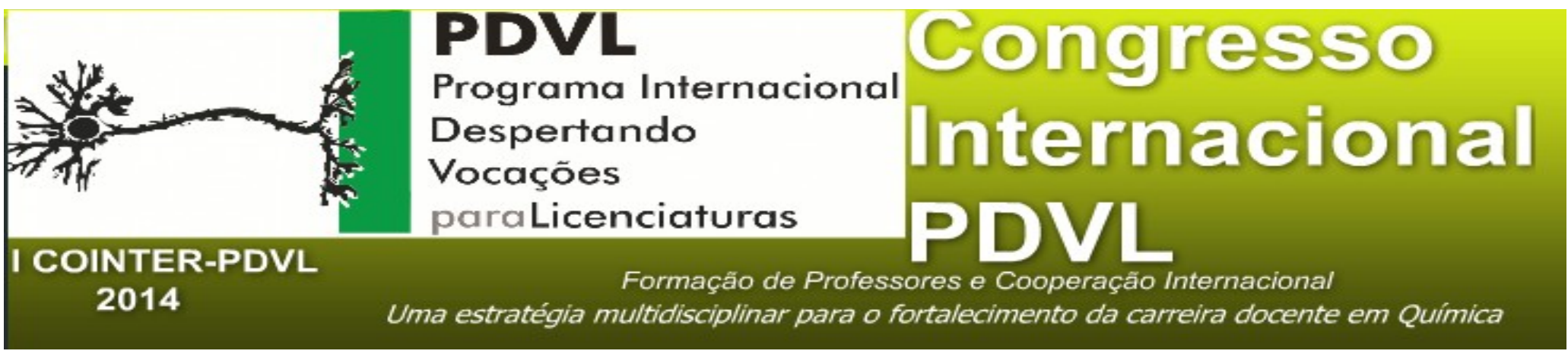

\title{
APRENDENDO QUÍMICA BRINCANDO: APLICAÇÃO DE JOGOS DIDÁTICOS PARA O APRENDIZADO DA QUÍMICA NO ENSINO FUNDAMENTAL
}

\begin{abstract}
Apresentação: Comunicação Oral
Bárbara Elizabeth Alves de Magalhães ${ }^{1}$; Alexandre Gomes Marques de Freitas²; Rafael Santos de Aquino $^{3}$; Tiago Santos Silva ${ }^{4}$
\end{abstract}

\section{Resumo}

Este trabalho tem por objetivo divulgar um estudo acerca da experimentação contextualizada com o cotidiano e da elaboração, aplicação e contribuição de jogos didáticos sobre métodos de separação de misturas para o ensino de Química nas aulas de Ciências no Ensino Fundamental. O estudo, embasado Teoria da Aprendizagem Significativa de Ausubel analisou a aprendizagem dos alunos de duas turmas do nono ano do Ensino Fundamental da Escola Estadual Dom Idílio José Soares, localizada no município de Ouricuri, Pernambuco, Brasil. Foram utilizados materiais conhecidos do cotidiano dos alunos para preparar diferentes misturas, sendo solicitado a cada um dos cinco grupos de alunos propor o máximo de métodos para separá-las, expondo suas propostas aos demais colegas para promover socialização e debate. Foram elaborados e aplicados cinco jogos didáticos sobre métodos de separação de misturas (dominó, jogo da memória, palavras cruzadas, caça-palavras e corrida química), devido ao fato das turmas serem numerosas e apenas um jogo não ser suficiente para integrar todos e com o intuito de permitir aos alunos escolher o jogo com o qual mais se

1 Licenciatura Plena em Química/IF Sertão Pernambucano Campus Ouricuri/barbara.elisabeth@hotmail.com

2 Licenciatura Plena em Química/IF Sertão Pernambucano Campus Ouricuri/alexandremarquesbdc@yahoo.com.br

3 Zootecnista/IF Sertão Pernambucano Campus Ouricuri/4 Médico Veterinário/IF Sertão Pernambucano Campus Ouricuri/tiagoifsertao@gmail.com 
identifique. Para a obtenção dos dados, além de observação direta, foi comparado o rendimento dos alunos nas atividades avaliativas, que foram aplicadas antes e depois da execução dos experimentos e jogos didáticos. Os resultados obtidos demonstraram a viabilidade da intervenção proposta e a contribuição significativa para o processo de ensino-aprendizagem do conteúdo em questão, criando um ambiente descontraído e motivador para o aprimoramento dos conhecimentos desenvolvidos nas aulas.

Palavras-Chave: experimentação, ludicidade, ensino, Ciências.

\section{Introdução}

É nas aulas de Ciências do nono ano do Ensino Fundamental que a maioria dos alunos tem o primeiro contato com o mundo da Química, até então despercebido. Esse contato pode despertar o interesse ou desmotivar os alunos a cerca desse mundo, de modo geral, dependendo da forma como a disciplina é apresentada. As aulas voltadas para a metodologia tradicional geralmente causam resistência por parte dos alunos em relação à Química, portanto, é preciso desvencilhar-se do tradicional e buscar realizar aulas diferenciadas, mais prazerosas e dinâmicas (SAIDELLES et al., 2012).

Tendo em vista que são muitas as possibilidades para melhorar o processo de ensinoaprendizagem da disciplina de Química, o presente estudo objetivou investigar as principais dificuldades enfrentadas pelos professores e alunos no que se refere ao ensino de Química no nono ano do Ensino Fundamental e buscar uma melhoria no ensino, propondo uma metodologia capaz de tornar mais prazeroso e eficiente o processo de ensino-aprendizagem da disciplina de Ciências. A pesquisa foi aplicada durante a execução do Estágio Supervisionado I, realizado no período de março a maio de 2014 em duas turmas de $9^{\circ}$ ano do ensino fundamental da Escola Estadual Dom Idílio José Soares, em Ouricuri-PE,

A partir das experiências vivenciadas nas etapas de observação e participação do estágio, contatou-se que muitos alunos aproveitavam o tempo livre das aulas na biblioteca, com jogos disponíveis na escola, como dominó convencional, damas, xadrez, quebra-cabeças e jogos da memória. Quanto ao desenvolvimento das aulas de Ciências, prioritariamente centrada no livro didático e limitada a mera exposição teórica, foi percebido que os alunos não se mostravam interessados, não eram capazes de enxergar o conteúdo estudado em sua realidade e não conseguiam elaborar conceitos por si só, apenas memorizando e reproduzindo nas avaliações os conceitos trazidos no livro.

Os professores devem buscar tornar a aprendizagem do aluno significativa, promovendo a 
interação entre os novos conhecimentos e seus conhecimentos acumulados, trabalhando temas de acordo com a realidade dos alunos (MAIA et al., 2005). Objetivando integrar os interesses dos alunos e minimizar os principais fatores que dificultam a aprendizagem dos conhecimentos específicos da Química, na etapa de regência do estágio foi adotada uma metodologia diferenciada. O conteúdo de métodos de separação de misturas foi abordado através de aula teórica com auxílio de recursos multimídia, aplicação de jogos didáticos, experimentação com materiais conhecidos do cotidiano dos alunos e debate em sala.

\section{Fundamentação Teórica}

O professor de Química precisa sempre buscar metodologias para despertar o interesse dos alunos pela disciplina e assumir o papel de mediador do conhecimento, permitindo ao aluno ser ativo na construção de seus conhecimentos, criando cidadãos críticos, capazes de participar ativamente da sociedade.

A abordagem de acontecimentos do cotidiano pode contribuir muito para o processo de ensino-aprendizagem de Química, despertando o interesse dos alunos e mostrando aos alunos que a Química, muitas vezes considerada uma disciplina abstrata, é algo útil e significativo. Permitindo que os alunos relacionem os conteúdos específicos da disciplina com seu dia a dia é possível superar as dificuldades de aprendizagem de vários conceitos (VIEIRA et al., 2010).

A principal dificuldade no ensino de Ciências está relacionada às deficiências estruturais da escola, à falta de profissionais capacitados e de laboratórios equipados, o que limita a possibilidade de realizar aulas experimentais e prejudica a aproximação dos estudantes com os conhecimentos específicos, que comprovadamente auxiliam na aprendizagem (FRANÇA et al., 2012).

Para realizar experimentos ou demonstrações em sala de aula não é necessário um laboratório completo, haja vista que é possível adaptar a maioria das atividades sem prejudicar os objetivos da aprendizagem, substituindo materiais convencionais de laboratório por alternativas do cotidiano, como recipientes simples, produtos de limpeza e substâncias encontradas em farmácias e supermercados (RUBINGER e BRAATHEN, 2012).

Segundo Piletti (2012), o método de trabalho em grupo oferece ao aluno a oportunidade de trocar ideias e opiniões, desenvolver habilidades necessárias à prática da convivência, completar, enriquecer e fixar conhecimentos, atender às diferenças individuais, desenvolver o senso de responsabilidade, a criatividade e o espírito de cooperação. 
A ludicidade condiz com os pressupostos da Teoria de Aprendizagem de Ausubel, que propõe como um dos fatores que possibilitam a ocorrência da aprendizagem significativa o fato do aprendiz manifestar uma disposição para aprender, tendo em vista que se o aluno não estiver disposto a aprender, a aprendizagem será mecânica e não significativa. Essa metodologia alternativa pode auxiliar na apropriação dos conteúdos, gerando uma aprendizagem significativa (CASTRO e COSTA, 2011).

O jogo didático insere atividades prazerosas nas aulas, instiga o estudante, propicia a construção e o aperfeiçoamento da aprendizagem dos conteúdos, atuando o professor como condutor e avaliador da aprendizagem (SAIDELLES et al., 2012). De acordo com Cunha (2012), constituem-se jogos no ensino as atividades diferenciadas constituídas por regras e controladas pelo professor, comprometidas com a aprendizagem, sem que se percam suas características lúdica e de liberdade. Os jogos podem ser usados como recurso didático de diferentes formas, dependendo de suas características e do planejamento do professor, mas não devem ser levados para aula simplesmente para torna-la mais descontraída.

\section{Metodologia}

A pesquisa realizada combina as metodologias quantitativa e qualitativa, foi realizada no ano de 2014 e analisou a aprendizagem de 78 alunos de duas turmas do nono ano do Ensino Fundamental da Escola Estadual Dom Idílio José Soares, localizada no município de Ouricuri-PE.

$\mathrm{Na}$ abordagem do conteúdo de separação de misturas, inicialmente foram minitradas aulas expositivas e dialogadas, retomados conteúdos já estudados e enfatizando os princípios químicos e físicos de cada método, explicitando os materiais e equipamentos necessários e apontando suas principais aplicações. O projetor multimídia foi usado para mostrar as imagens dos equipamentos necessários a cada método, haja vista que a escola dispõe de poucos equipamentos, e algumas fotos e vídeos das principais aplicações dos métodos.

É muito importante mostrar ao aluno que a Química está presente no mundo que o cerca, principalmente através da experimentação e da contextualização, assim o aluno pode perceber que a Química não é algo absolutamente abstrato e distante de sua realidade, por isso foi realizada demonstração experimental em sala de aula, porque a escola não tem laboratório. Mesclando vidrarias e equipamentos convencionais de laboratório e materiais alternativos (materiais e substâncias conhecidas do cotidiano dos alunos) disponíveis na escola, foram demonstrados alguns 
métodos de separação de misturas e relembrados conceitos: substâncias e misturas, homogêneas e heterogêneas, fases, componentes e sistemas químicos.

A aula experimental é um instrumento muito eficaz para o ensino de Química, mas para melhorar o entendimento dos conteúdos específicos, os experimentos não devem ser meras ilustrações da teoria já explicitada pelo professor. Para que a experimentação promova uma aprendizagem significativa e desperte o interesse dos alunos é importante que o professor permita a exposição e discussão de opiniões durante a realização do experimento, desse modo será oportunizado que os alunos relacionem o experimento realizado com o conteúdo, facilitando a compreensão por parte dos alunos (RUBINGER e BRAATHEN, 2012).

Objetivando aproximar o conteúdo da realidade dos alunos, através da experimentação contextualizada com o cotidiano dos alunos, foram preparadas seis misturas (apresentadas na figura 1) com substâncias conhecidas dos alunos, que poderiam ser separadas de acordo com métodos apresentados na aula expositiva. Os alunos de cada turma se organizaram em cinco grupos, e foi solicitado a cada grupo escolher uma das mistura e propor o máximo de métodos para separá-las, podendo utilizar materiais de laboratório e alternativos disponíveis na escola para testar os métodos propostos. Durante a socialização das respostas cada grupo expôs suas ideias e os demais alunos da turma poderiam questionar os métodos propostos ou sugerir outros métodos. A mistura que não foi escolhida por nenhum dos grupos foi usada para a socialização e debate com todos os alunos.

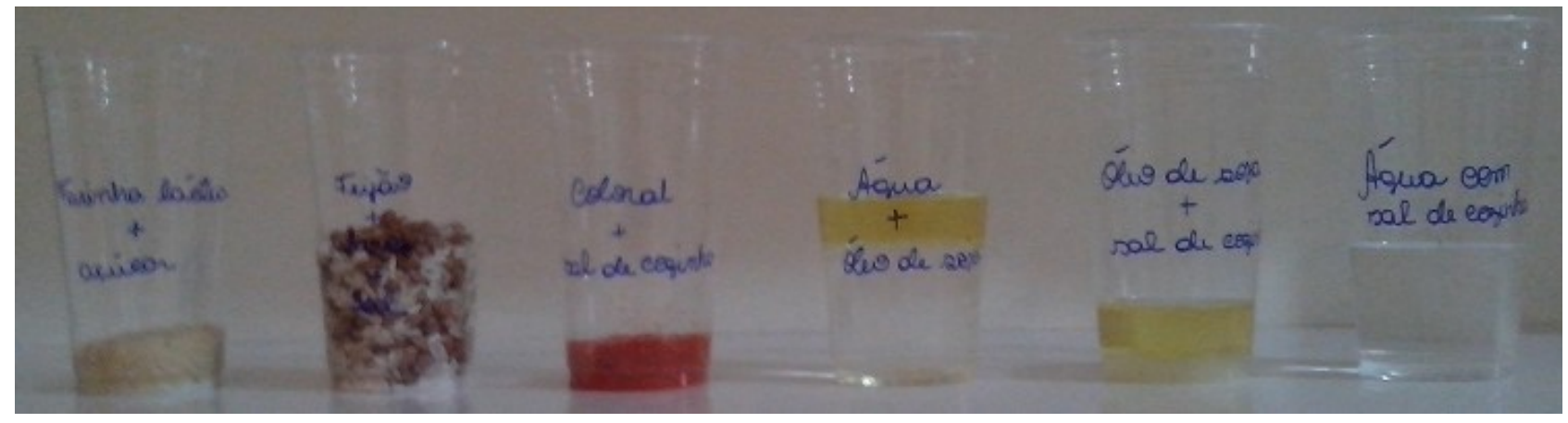

Figura 1: misturas com substâncias conhecidas dos alunos

Conhecendo o interesse de muitos alunos das turmas, foram elaborados e aplicados cinco jogos didáticos sobre métodos de separação de misturas: dominó, jogo da memória, palavras cruzadas, caça-palavras e corrida química. A produção de mais de um jogo se deu devido ao fato das turmas serem numerosas e apenas um jogo não ser suficiente para integrar todos os alunos e com o intuito de permitir aos grupos escolher o jogo com o qual mais se identifique, possibilitando ao aluno compreender o conteúdo assimilando-o ao jogo que gosta. Os grupos ficaram sob 
supervisão constante para promover uma aprendizagem significativa sobre o conteúdo, evitando que conceitos errôneos fossem formados.

A utilização dos jogos auxilia o processo de ensino-aprendizagem de Química e promove uma maior participação dos alunos em sala de aula (SAIDELLES et al., 2012). Para a escolha adequada do jogo didático é imprescindível que sejam considerados os aspectos motivacional e de coerência, o primeiro reflete o interesse dos alunos e o equilíbrio entre as funções lúdica e educativa, enquanto o último refere-se às regras, objetivos pedagógicos e materiais utilizados (CUNHA, 2012).

O jogo de dominó, apresentado na figura 2, é composto por 19 peças, que contem informações a cerca do princípio, equipamentos necessários ou exemplos para correlacionar ao nome métodos de separação de misturas. Propõe-se que joguem seis alunos que peguem três peças cada ou, três duplas que peguem seis peças cada, e a peça não selecionada deve iniciar o jogo. Caso o jogador ou a dupla não possuam a peça necessária a vez é passada. Quando todas as peças forem lançadas, vence o jogo.

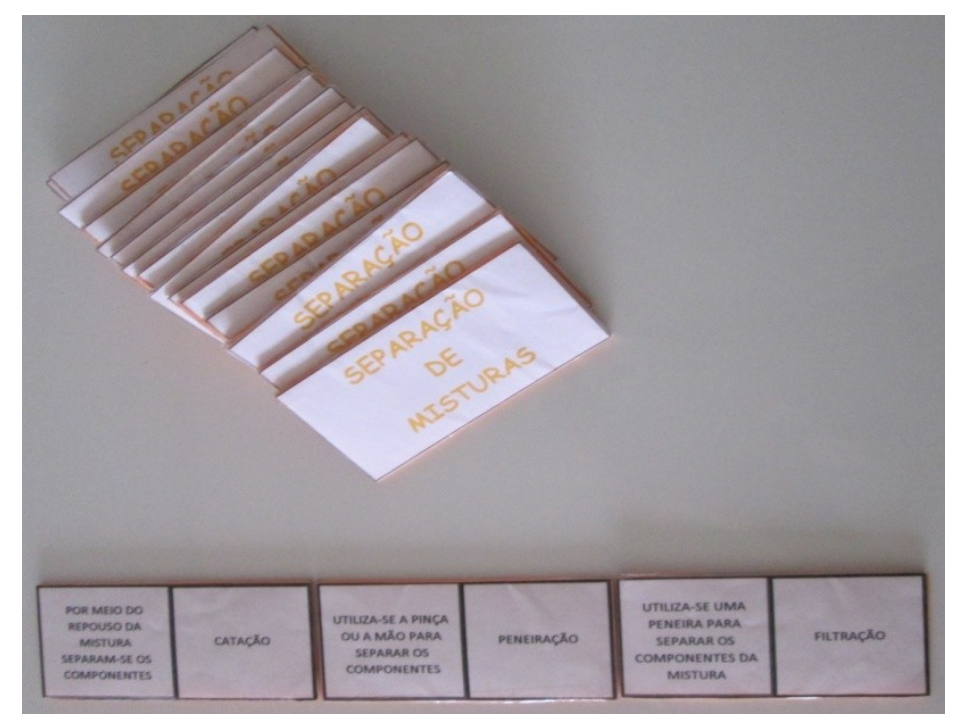

Figura 2: jogo dominó sobre separação de misturas

O jogo da memória é composto por 40 peças no total, que devem formar 20 pares. As peças devem ser embaralhadas com a face colorida voltada para cima. Cada peça azul contém a imagem exemplificando o método de separação de mistura e há uma peça roxa correspondente com o nome do método, como mostra a figura 3. Não é fixado um número de jogadores, mas independente do número de jogadores, vence o que tiver encontrado mais pares. 


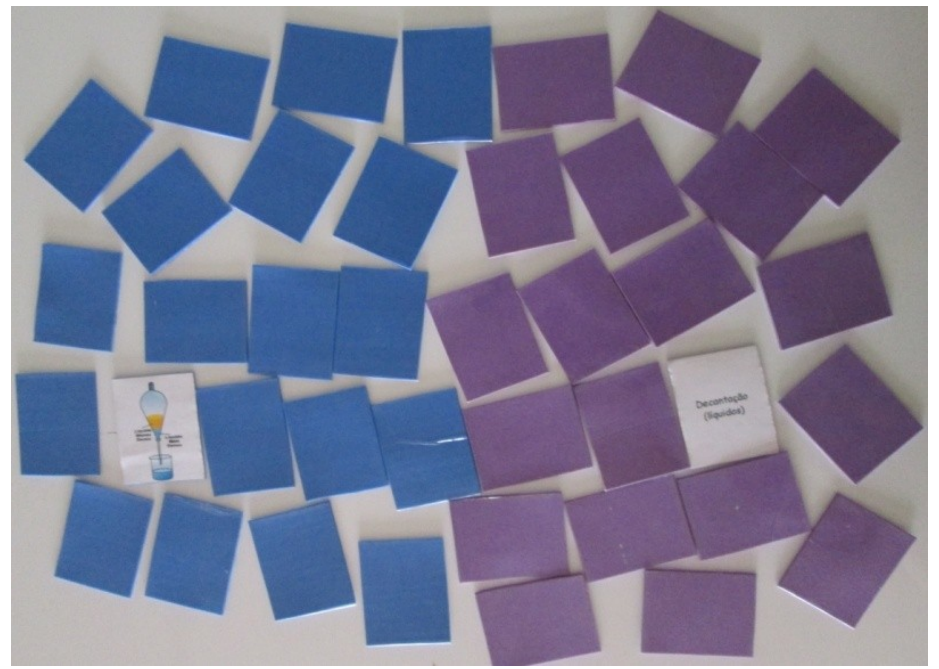

Figura 3: jogo da memória sobre separação de misturas

No jogo de palavras cruzadas (figura 4 à esquerda), para cada informação a cerca dos métodos de separação de misturas apresentada ao final da página há uma palavra correspondente, que preenche corretamente os espaços em branco. No jogo de caça-palavras (figura 4 à direita), as informações presentes no início da página correspondem às palavras dispersas no quadro.

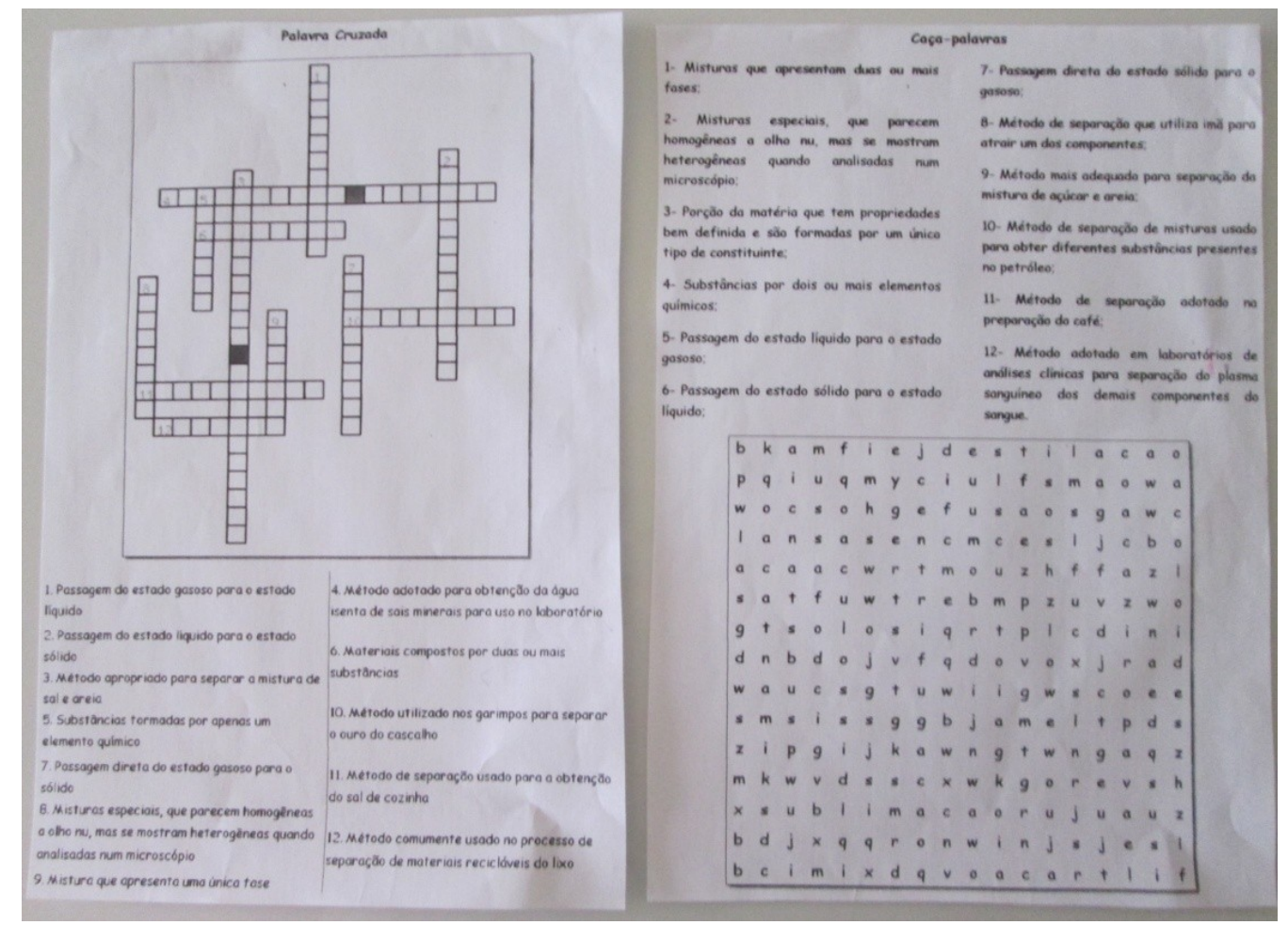

Figura 4: jogos palavra cruzada e caça-palavras sobre separação de misturas

Para o jogo corrida química é proposto que joguem três duplas, representadas por uma peça sobre o tabuleiro, que contém 32 espaços, como pode ser visto na figura 5 . O dado deve ser lançado para indicar quantos espaços devem ser percorridos. Espaços que contém a imagem de um cadeado 
correspondem a uma carta com o mesmo símbolo, que no verso tem a imagem do método de separação de mistura e uma pergunta relacionada e os espaços que contém uma interrogação correspondem a um cartão com uma pergunta de múltipla escolha. Caso a dupla não saiba responder a pergunta proposta, volta sua peça para o espaço onde estava anteriormente. Cada dupla tem direito a uma ajuda ao longo do jogo, para tanto deve escolher ao acaso um dos quatro cartões disponíveis, que devem ser embaralhados ao início de cada jogo. Vencerá o jogo a dupla que levar sua peça primeiro ao ponto de chegada. Para a execução desse jogo é importante um mediador, que pode ser o professor.

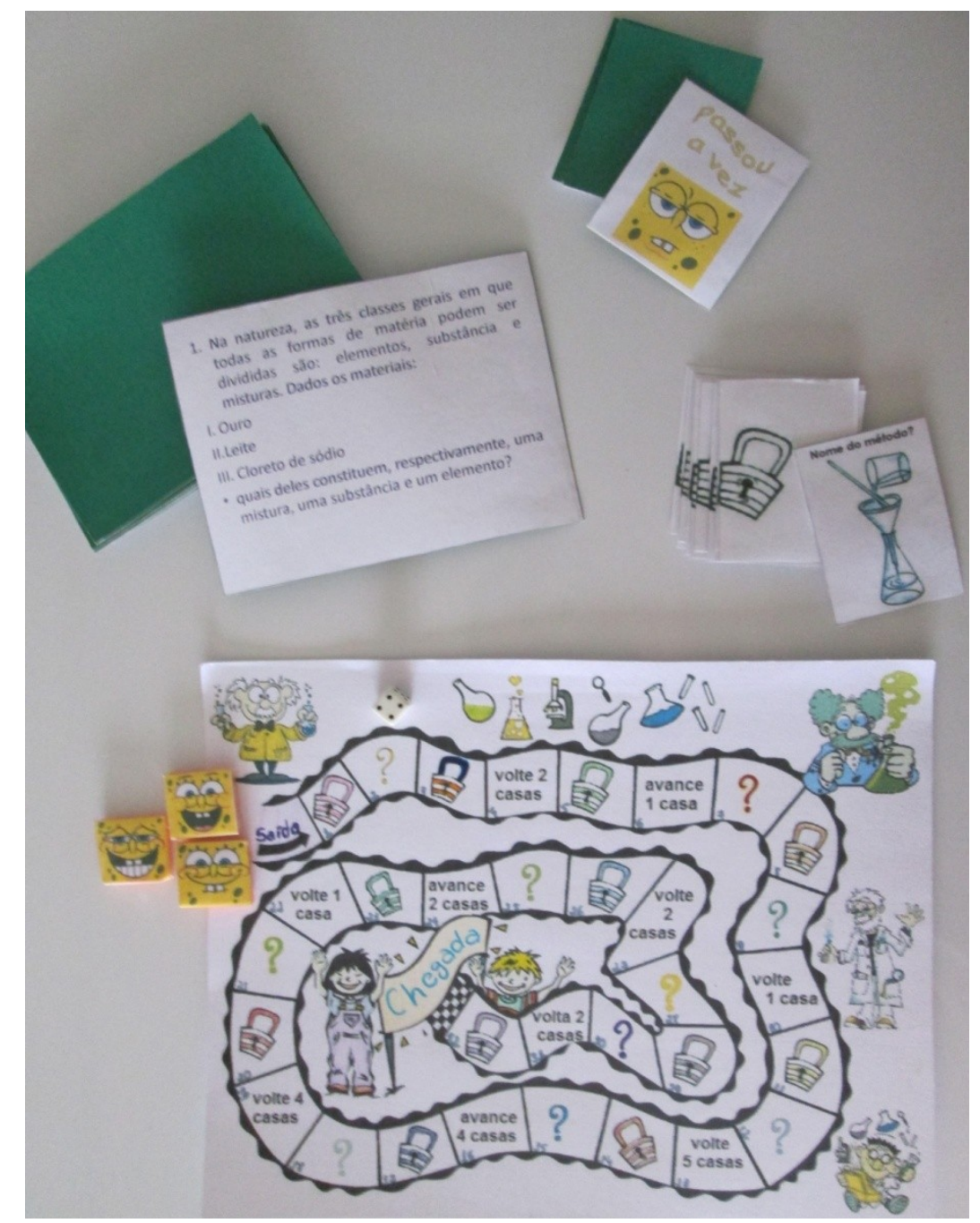

Figura 5: jogo corrida química sobre separação de misturas

Findada a abordagem do conteúdo de métodos de separação de mistura, depois da socialização dos experimentos e jogos didáticos, foi aplicado um questionário com oito questões para conhecer as opiniões e avaliar a aceitação dos alunos em relação a esse tipo de aula. 


\section{Resultados e Discussões}

Na observação direta foram constatados o bom desempenho, o interesse e prazer dos alunos no desenvolvimento das atividades propostas. As respostas apresentadas no gráfico a seguir correspondem às perguntas feitas no questionário aplicado: consegue aprender com aulas apenas teóricas (1), já havia tido aulas com experimentos (2), já tinha tido aulas com jogos sobre assuntos estudados (3), relacionando os conteúdos com o cotidiano é mais fácil aprender (4), foi mais fácil aprender com os experimentos (5), com os jogos foi mais fácil aprender (6), gostaria de ter mais aulas diferenciadas (7).

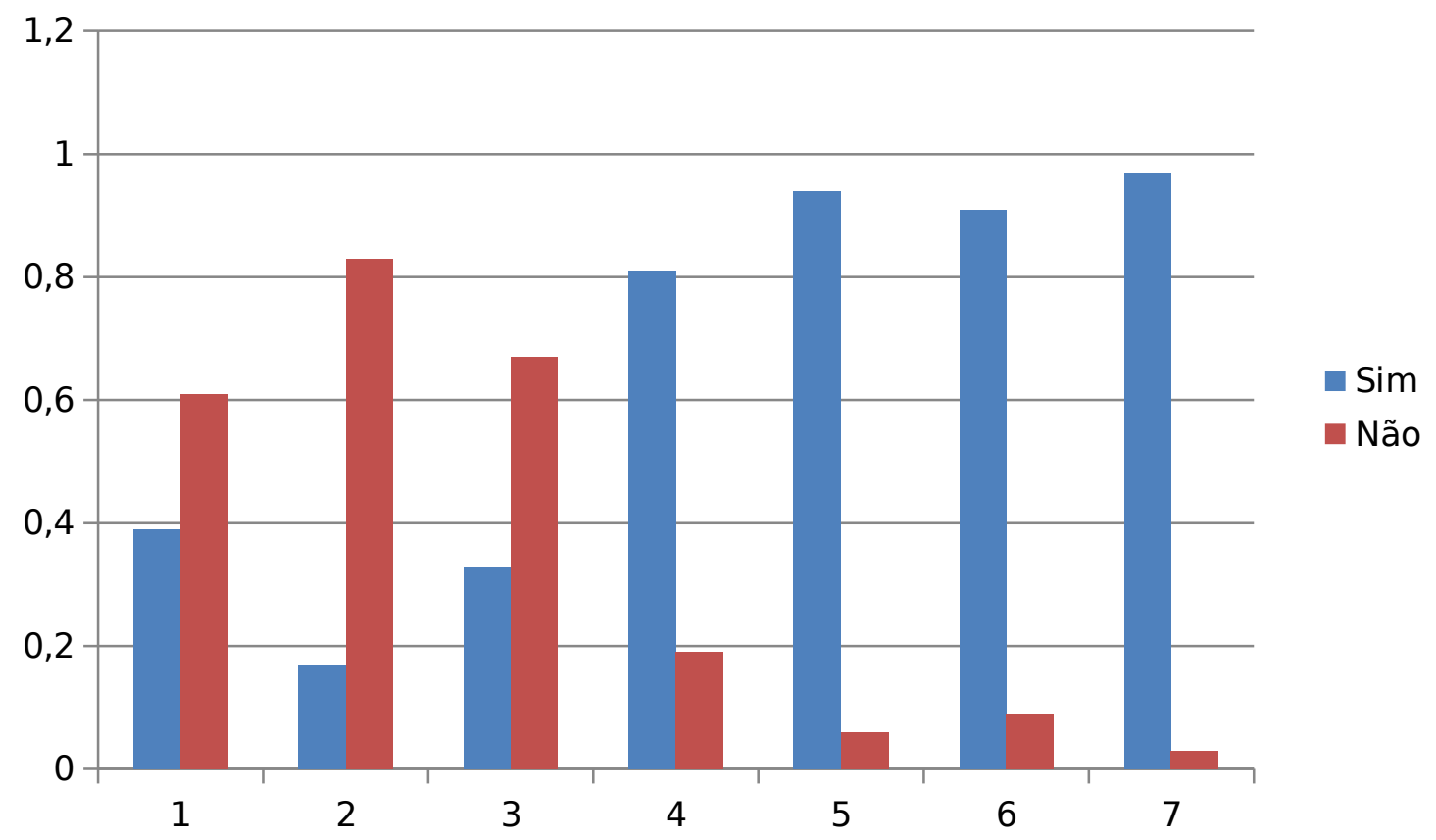

Gráfico 1: respostas dos alunos no questionário

A última das oito perguntas do questionário foi uma autoavaliação do aprendizado a partir dos experimentos e jogos, como ruim, regular, bom ou ótimo. Dos alunos, 22\% indicaram que seu aprendizado foi ótimo e 78\% apontaram que seu aprendizado foi bom.

É importante que sejam adotados métodos de ensino que estimulem o aprendizado do aluno e permitam ao aluno aprender a Química com mais facilidade e identificá-la no cotidiano (FRANÇA et al., 2012). As atividades lúdicas em sala de aula, principalmente os jogos didáticos, são um instrumento didático que permite o aprendizado de forma mais simples e prazeroso, sendo um elemento motivador para o Ensino da Química (CASTRO e COSTA, 2011). 
Foram comparadas as notas obtidas pelos alunos em atividades avaliativas embasadas apenas no método tradicional e as notas obtidas pelos alunos em atividades aplicadas após discussão dos experimentos e jogos didáticos. A partir desse comparativo foi identificado que $64 \%$ dos alunos apresentaram um aumento significativo na nota média $(7,0)$. Nas atividades avaliativas embasadas no método tradicional 54\% dos alunos não haviam atingido a nota média, percentual que caiu para 19\% após a adoção de aulas diferenciadas, como mostra o gráfico 2.

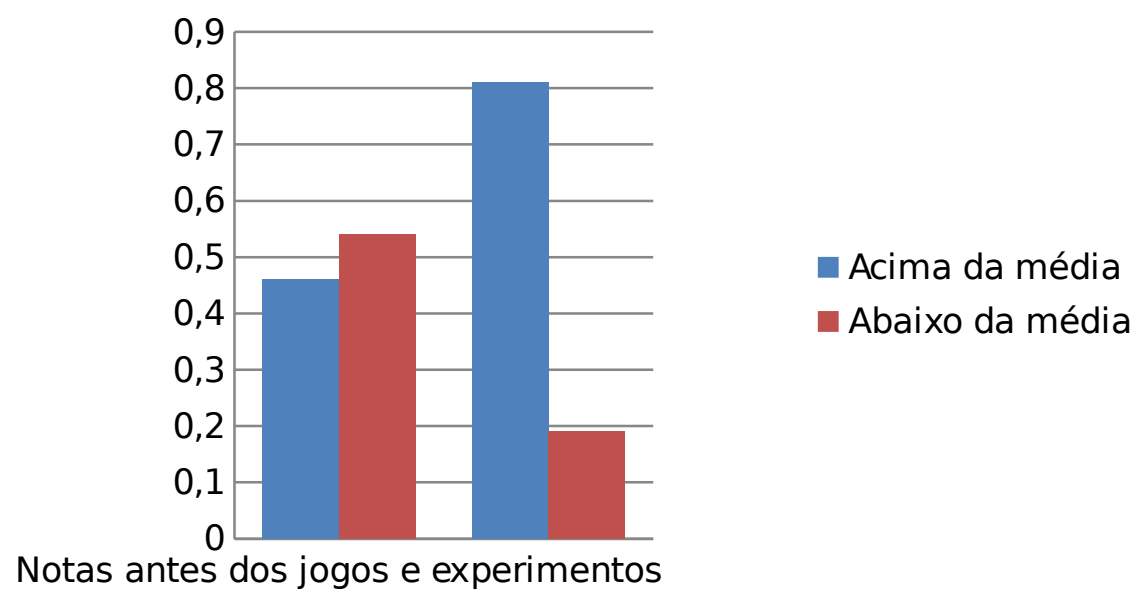

Gráfico 2: comparativo as notas obtidas pelos alunos

Os resultados obtidos demonstram que em aulas diferenciadas, em que se promove a experimentação, o diálogo e a aplicação de jogos, cria-se um ambiente descontraído e motivador, que contribui positivamente para o processo de ensino-aprendizagem e permite o aprimoramento dos conhecimentos desenvolvidos nas aulas, favorecendo uma aprendizagem significativa por parte dos alunos.

\section{Conclusões}

Os alunos se interessam muito mais pelo que conhecem e faz parte do seu cotidiano do que por teorias que lhes parecem desconectadas da realidade, portanto faz-se necessário que o professor adote estratégias diversificadas para o ensino da Química, rompendo com a metodologia tradicional de ensino e buscando facilitar o processo de ensino-aprendizagem. A experimentação, a contextualização, o debate e a aplicação de jogos didáticos podem ser adotados nas aulas de Ciências para proporcionar uma aprendizagem significativa a cerca dos conhecimentos específicos da Química. 
Nas atividades propostas para este estudo observou-se o interesse, o bom desempenho no desenvolvimento das atividades propostas e prazer dos alunos em estar aprendendo conceitos de química. A partir dos resultados obtidos e da observação direta, conclui-se que o diálogo, a experimentação, a contextualização e os jogos didáticos criam um ambiente que contribui significativa para o processo de ensino-aprendizagem de Ciências acerca do conteúdo de métodos de separação de misturas.

Considerando que o conteúdo de métodos de separação de misturas é reapresentado na disciplina de Química no primeiro ano do Ensino Médio, as atividades diferenciadas apresentadas neste estudo também podem ser aplicadas com esses alunos objetivando promover uma aprendizagem significativa.

\section{Referências}

CASTRO, Bruna Jamila de; COSTA, Priscila Caroza Frasson. Contribuições de um jogo didático para o processo de ensino e aprendizagem de Química no Ensino Fundamental segundo o contexto da Aprendizagem Significativa. Revista electrónica de investigación en educación en ciências. v. 6, n. 2, p. 1-13, 2011.

CUNHA, Marcia Borin da. Jogos no Ensino de Química: Considerações Teóricas para sua Utilização em Sala de Aula. Química Nova na Escola. v. 34, n. 2, p. 92-98, 2012.

FRANÇA, M. C. et al. Recurso didático alternativo para aula de eletroquímica. II Congresso Internacional de Educação Científica e Tecnológica, Santo Ângelo, 2012.

MAIA, Daltamir J. et al. Um experimento para introduzir conceitos de equilíbrio químico e acidez no Ensino Médio. Química Nova na Escola. n. 26, p. 44-46, 2005.

PILETTI, C. Didática geral. 24. ed. São Paulo: Ática, 2012.

RUBINGER, M. M. M.; BRAATHEN, P. C. Ação e reação: ideias para aulas especiais de química. $1^{\mathrm{a}}$ edição. ed. Belo Horizonte: RHJ, 2012. 
Otávio Lavarda; SANTOS, Douglas Silva dos; SANTOS, Nara Rejane Zamberlan dos. Jogo didático como auxiliar para o aprendizado em química. 2012.

VIEIRA, C. A. et al. Produção de "kits" com materiais alternativos para emperimentação no ensino médio. Professores em Formação, v. 1, 2010. 